\title{
Investigation of genes coding for anti-HIV proteins MAP30 and MRK29 from Thai bitter melon (Momordica charantia L.)
}

\author{
Paktraporn Mekloy${ }^{1}$, Krisada Sakchaisri², Weena Jiratchariyakul1, Somnuk Bunsupa ${ }^{1 *}$ \\ 1 Department of Pharmacognosy, Faculty of Pharmacy, Mahidol University, Bangkok, Thailand \\ 2 Department of Pharmacology, Faculty of Pharmacy, Mahidol University, Bangkok, Thailand
}

\begin{abstract}
Thai bitter melon, or Ma-Ra-Khee-Nok, is an M. charantia L. variety that is widely cultivated in Thailand. Thai bitter melon exhibits various pharmacological activities, including antidiabetic and antiviral. Many phytochemicals are found in various parts of this plant, notably ribosome-inactivating proteins (RIPs) in fruits and seeds. MAP30 is a well-known type I RIP isolated from seeds of the Chinese bitter melon. MAP30 exhibits various pharmacological activities, such as cytotoxicity and anti-HIV activity. However, there are no reports on MAP30 sequence information in Thai bitter melons. There have been only reported on MRK29 protein which exhibits anti-HIV reverse transcriptase activity, but only 20 amino acid sequences from the $\mathrm{N}$-terminal were identified. In this study, we obtained 17 sequences with a high nucleotide sequence identity (>99\%) with MAP30. Of these, one sequence (McRIP001) had double substitutions at the leading sequence, twelve partial (mature) sequences had an identity of 100\%, and two sequences (McRIP002) had a single substitution (silent mutation) at the same position. Moreover, two sequences, McRIP003 and McRIP004, had a single substitution at different positions. Phylogenetic analysis of amino acid sequences demonstrated a close relationship between the obtained sequences and MAP30. Homology modelling revealed that the mutation points did not involve RNA $N$ glycosidase active sites. The cloning of MRK29 was unsuccessful due to the limit of available information. The present study provides a valuable reference for further research and quality control of healthcare products from Thai bitter melon.
\end{abstract}

\section{Keywords:}

Momordica charantia, Thai bitter melon, MAP30, MRK29, Anti-HIV

\section{INTRODUCTION}

Momordica charantia L. (M. charantia), also known as bitter melon, belongs to the Cucurbitaceae family. $M$. charantia is cultivated in many regions globally, including Asia, South America, and Africa. It has many varieties and local names, including the Chinese variety (lai-pu-tao, ku-gua), Japanese variety (goya), Indian variety (karela), Vietnamese variety (la khoqua), and Thai variety (mara) ${ }^{1,2}$. Varieties differ substantially in the shape and bitterness of the fruit. However, they have the same scientific name as Momordica charantia L. ${ }^{3}$. The plant has been widely used as herbal anti-aging medicine. Major pharmacological activities that have been observed in bitter melon include abortifacient, antidiabetic, antibacterial, antiviral, and antitumor ${ }^{4}$. These characteristics have been correlated with the presence of phytochemicals, including saponins, alkaloids, triterpenes, steroids, and proteins. Several compounds have been isolated from all plant parts, such as momordicins, charantins, cucurbitins, and goyaglycosides ${ }^{5}$. Charantins, a mixture of steroidal saponins found in the fruits of $M$. charantia exhibit hypoglycaemic activity ${ }^{6,7}$. Many proteins and peptides which possess RNA $N$-glycosidase, DNase-like, antitumor, immunosuppressive, and antimicrobial activities have also been isolated, such as

*Corresponding author:

*Somnuk Bunsupa somnuk.bun@mahidol.ac.th 
ribosome-inactivating proteins (RIPs), momordica anti-HIV protein of $30 \mathrm{kDa}$ (MAP30), and momorcharins $(\mathrm{MMC})^{8}$. These compounds are of interest to researchers and have been studied to confirm their pharmacological activities.

RIPs are a highly toxic protein family characterised by rRNA $N$-glycosidase (EC 3.2.2.22) that has been identified in plants, fungi, algae, and bacteria9 RIPs can cleave a specific base adenine $\left(\mathrm{A}_{4234}\right)$ from the 28s ribosomal RNA (rRNA) of the eukaryotic ribosome. In addition to RNA $N$-glycosidase activity, RIPs also exhibit adenosine glycosidase, RNase, DNase-like, superoxide dismutase, anti-HIV, and antimicrobial activities $^{10-15}$. RIPs can be categorised into three types: RIPs with a single polypeptide (enzymatic subunit, chain A) are classified as type I, the structure with chain A binding to a lectin-like subunit (chain B) with a disulphide bond is classified as type II, and the synthesised precursor or inactive form with a domain similar to type I is classified as type III $^{8,16-17}$.

MAP30 is a well-known type I RIP isolated from the seeds of $M$. charantia. MAP30, which has a molecular weight of $30 \mathrm{kDa}$, consists of 287 amino acids 18-19 and exhibits various pharmacological activities, particularly cytotoxic activity in various cancer cell lines, such as bladder cancer, melanoma, prostate carcinoma, and breast cancer ${ }^{20-21}$. It has been reported that MAP30 can downregulate the expression of HER2, a human epidermal growth factor receptor-2. Overexpression of HER2 has been observed in many human breast cancers. Thus, MAP30 has the potential for development as an anti-breast cancer therapy ${ }^{22-23}$. Additionally, MAP30 has been observed to inhibit HIV-1 reverse transcription, integration, and syncytium formation between infected and new white blood cell ${ }^{24-25}$. Moreover, it has been reported that $\alpha$-momorcharin $(\alpha$-MMC) from $M$. charantia exhibits similar bioactivities as MAP30 ${ }^{26}$. The molecular weight of $\alpha$-MMC is $29 \mathrm{kD}^{27}$, which is slightly different from that of MAP30. These two proteins were confirmed as glycoproteins which displayed an inhibitory effect on lung adenocarcinoma A549 cell ${ }^{28}$. In addition, $\alpha$-MMC also shows an immunosuppressive effect ${ }^{29}$ and stimulates inflammatory responses in human monocytes ${ }^{30}$.

Thai bitter melon, or Ma-Ra-Khee-Nok, is an M. charantia variety, known to have the smallest fruit of all bitter melons. This variety is cultivated in Thailand $^{31}$. It has been used as a vegetable in Thai traditional medicine as a bitter tonic, antipyretic, anthelmintic, laxative, and antidiabetic ${ }^{32}$. Furthermore, fruit powder in various dosage forms, including capsules, tablets, and infusions, are included in the national drug lists of Thailand for antipyretics and bitter tonics ${ }^{33}$. Thai bitter melon has also been used as a food supplement to lower blood sugar levels (to treat hyperglycaemia) in diabetic patients. Several studies have suggested that hypoglycaemic activity is caused by an increase in insulin activity $^{2,34-35}$.

Bitter melon proteins have been found in many parts of the plant, especially fruits and seeds. These proteins have been reported to act as $\mathrm{N}$-glycosidases, which were identified as RIPs ${ }^{8,36}$. Thai bitter melon protein (MRK29) with a molecular weight of 28.6 $\mathrm{kDa}$ was reported to have anti-HIV reverse transcriptase activity, which exhibited a significant reduction in viral core protein p24 expression in HIV-infected cells ${ }^{24}$. MRK29 has several amino acid residues different from MAP30 and has been suggested as a new type I RIPs ${ }^{24}$. Thus, MAP30 and MRK29 are good candidates for the further development of new drugs to treat HIV. However, it is costly and difficult to purify a large amount of MRK29 from plants. Therefore, the production of recombinant MRK29 in a suitable host is required to solve this problem. In this regard, information on the MRK29 coding sequence is required. However, only 20 amino acid sequences from the $\mathrm{N}$-terminal have been identified $^{24}$. Likewise, there are no reports on MAP30 sequence information in Thai bitter melon.

In this study, to gain new insight into MAP30 and MRK29 from Thai bitter melon, we successfully cloned the full-length MAP30 candidates using degenerate and gene-specific primers. The active site and protein folding of the obtained sequences were further investigated by molecular modelling. Our results confirmed the occurrence of MAP30 and suggested the existence of MRK29 in Thai bitter melon.

\section{MATERIALS AND METHODS}

\subsection{Plant materials}

M. charantia seeds were purchased from a commercial distributor (Chiatai, Bangkok, Thailand) and grown on vermiculite for 21-28 days before being transferred to soil. The plants were maintained at $25 \pm 2^{\circ} \mathrm{C}$ with a $16 \mathrm{~h}$ photoperiod (light intensity at 3000 lx) before harvesting the stems and leaves. Fresh $M$. charantia fruits were obtained from a local market in Bangkok, Thailand. Both plant specimens were identified and compared the morphology with voucher specimen (BKF. No. 100085, SN. 108121) from Prof. Dr. Weena Jiratchariyakul. The herbariums were kept at the Faculty of Pharmacy, Mahidol University, Thailand.

\subsection{DNA and RNA extraction}

Genomic DNA (gDNA) were prepared from the stems and leaves of $M$. charantia by soaking samples in liquid nitrogen and grinding them into a fine powder using a mortar and pestle. The samples were then subjected to extraction using a DNA extraction kit (RBC Bioscience, Taiwan) according to the manufacturer's protocol. Total RNA was extracted from fruit 
samples of $M$. charantia. The grinding processes were the same as those for gDNA extraction, but the RNeasy Plant Mini Kit (Qiagen, Germany) was used for extraction. Excess DNase treatment of the total RNA solution was performed to avoid DNA contamination. The quality of gDNA and RNA was checked by electrophoresis using $1-1.2 \%$ gel at $100 \mathrm{~V}$, and the gel was further stained with Visafe Green (Vivantis, Malaysia). The stained gel was scanned using the G:BOX system with the GeneSys software (SynGene, USA). The concentrations of gDNA and RNA were determined using a SmartSpecTM Plus spectrophotometer (Bio-Rad, USA). The obtained gDNA and RNA were stored at $-20^{\circ} \mathrm{C}$ before use.

Each total RNA sample was converted into cDNA using the RevertAid RT Reverse Transcription Kit (Thermo Scientific ${ }^{\text {TM }}$, USA). First-strand cDNA was synthesised using Oligo(dT)17-adaptor primer (OTA), and second-strand CDNA was synthesised using the adaptor_R primer (AR). The quality of cDNA was checked using $\beta$-tubulin primers ( $\beta$ Tub_F and $\beta$ Tub_R) (Table 1).

Table 1. List of primers in this study.

\begin{tabular}{lll}
\hline Primer & \multicolumn{1}{c}{ Sequence $\left(\mathbf{5}^{\prime}>\mathbf{3}^{\prime}\right)$} & Sef. \\
\hline F1 & GCGATGGTGGTATGCTTACTACT & DQ643967.1 \\
F4 & TACGTAATCTTCATTGGTGTTCCTGCTGCCAA & DQ643967.1 \\
F4* & TATCGTAATCTTCATTGGTGTTCTGCTGCCAA & S79450.1 \\
R1 & GGAATCTGTTGTGAATTGAGCGG & XP_022156707.1, P24817.2, ABG37691.1 \\
DF & GAYGTNAAYTTYMGNYTNWSN & - \\
$\beta$ Tub_F & CAGGGAGGAATACCCAGACA & - \\
$\beta$ Tub_R & GGCAGTGAATTGCTCACTCA & - \\
OTA & TTTTTTTTTTTTTTTTTTGATCTAGAGGTACCGGATCC & - \\
AR & TGATCTAGAGGTACCGGATCC & pJET1.2/blunt \\
pJET_F & CGACTCACTATAGGGAGAGCGGC & pJET1.2/blunt \\
pJET_R & AAGAACATCGATTTTCCATGGCAG & \\
\hline
\end{tabular}

\subsection{Amplification of RIPs}

Specific primers were designed using fulllength MAP30-1 ${ }^{3}$ (GenBank no. S79450.1), and MAP302(GenBank no. DQ643967.1) from Chinese bitter melon (Table 1). The degenerate primer (DF) was designed based on the consensus of conserved 20 amino acid fragments in the N-terminal between RIP I conserved ${ }^{37}$ and RIPs from $M$. charantia, including MRK2924 and $\alpha$ MMC $^{38}$ (accession no. XP_022156707.1), beta-momor$\operatorname{charin}^{36}(\beta$-MMC; accession no. P24817.2), and MAP303 (GenBank accession no. ABG37691.1).

The gDNA and cDNA were used as templates in a polymerase chain reaction (PCR) with KOD highfidelity DNA polymerase (TOYOBO, Japan). DNase/ RNase-free distilled water was purchased from Invitrogen. PCR was performed with an initial pre-denaturation at $94^{\circ} \mathrm{C}$ for $2 \mathrm{~min}$, followed by $25-30$ cycles each at $95^{\circ} \mathrm{C}$ for $10 \mathrm{~s}, 55-60^{\circ} \mathrm{C}$ for $30 \mathrm{~s}$, and $68^{\circ} \mathrm{C}$ for $30 \mathrm{~s}$; and a final extension at $68^{\circ} \mathrm{C}$ for $5 \mathrm{~min}$. The PCR products were cleaned using a GeneJET PCR purification kit (Thermo Scientific ${ }^{\mathrm{TM}}$, USA) and stored at $-20^{\circ} \mathrm{C}$ before use. The PCR products from the gDNA template were sequenced directly, while PCR products from cDNA were cloned before sequencing.

\subsection{RIP cloning}

The pJET1.2/blunt vector (Thermo Scientific ${ }^{\mathrm{TM}}$, USA) was used as the cloning vector. The purified PCR products were ligated with a cloning vector in a $3: 1$ ratio by T4 DNA ligase (Vivantis, Malaysia) at $4^{\circ} \mathrm{C}$ and incubated overnight. Competent E. coli (DH5 $\alpha$ ) was transformed by a heat-shock transformation in an Accublock dry bath (Labnet, USA) at $42^{\circ} \mathrm{C}$ for $45 \mathrm{~s}$ before immediately cooling on ice. Then, they were spread on $\mathrm{LB}$ agar $(100 \mathrm{mg} / \mathrm{mL}$ ampicillin $)$ and incubated at $37^{\circ} \mathrm{C}$ overnight.

The transformed colonies were cultured overnight in $\mathrm{LB}$ medium $(100 \mathrm{mg} / \mathrm{mL}$ ampicillin $)$ at $37^{\circ} \mathrm{C}$ and $200 \mathrm{rpm}$ in a shaking incubator. The cell pellets were collected by centrifugation at $4000 \mathrm{rpm}$ for $10 \mathrm{~min}$ at $4^{\circ} \mathrm{C}$. Then, the inserted vector was extracted using the GeneJET Plasmid Miniprep Kit (Thermo Scientific ${ }^{\mathrm{TM}}$, USA). The concentration of the purified plasmid was measured using a NANO DOT Microspectrophotometer (Hercuvan, USA).

\subsection{DNA sequencing}

The pJET_F and pJET_R primers were used with the pJET1.2 vector. The concentration of all samples was more than $50 \mathrm{ng} / \mu \mathrm{L}$ for the standard sequencing procedure outlined by Macrogen sequencing services (Macrogen Int., Seoul, South Korea).

\subsection{Sequence and phylogenetic analysis}

The obtained nucleotide and deduced amino acid sequences were searched in the NCBI database 
using BLASTN and BLASTP, respectively. The hit sequence with the highest score was selected as the reference sequence. Moreover, the amino acid sequences of plant RIPs were selected for further analysis. The nucleotide sequences were aligned using ClustalW from the biological sequence alignment editor (BioEdit) ${ }^{39}$. Multiple alignments were performed using molecular evolutionary genetics analysis version 10 (MEGA-X) ${ }^{40}$. Then, a phylogenetic tree was created using the neighbour-joining method with 1000 bootstrap replicates.

\subsection{Molecular modelling}

The predicted three-dimensional molecular structures of MAP30 and MRK29 candidates were predicted by SWISS-MODEL ${ }^{41}$ using MAP30- $3^{19}$ as the template. The obtained 3D structure of the sample was visualised using PyMOL (www.pymol.org).

\section{RESULTS AND DISCUSSION}

\subsection{Amplification of MAP30 and MRK29 candidates}

The MAP30 candidates were obtained from the gene-specific primer pairs F1-R1 and F4-R1. The band of the expected size of approximately 900-1000 bp of PCR products was obtained from both gDNA and cDNA templates (Figure 1). Thus, the PCR products from F1-R1 pairs were cleaned for further DNA sequencing, while the PCR products from F4-R1 pairs were cloned into a cloning vector. Unfortunately, no expected band of MRK29 candidate was obtained from DF-AR primer pairs. This result may be explained by the fact that the information from the MRK29 fragment is not sufficient to design the degenerate primer. The previous study of MRK2924 used conventional protein extraction, purification, and sequencing methods. In addition, MAP30 from Chinese bitter melon was cloned by using degenerate primers from two conserved regions which were identified by conventional methods ${ }^{42}$. Thus, Omics technologies, including genomics, transcriptomics, and proteomics may be needed to obtain more information on the MRK29 sequence.

\subsection{Cloning of MAP30 candidates}

The cloning of PCR products from F4-R1 primers was unsuccessful due to the lack of growth of positive colonies in liquid media for further plasmid extraction. This phenomenon may occur because of the basal expression of the toxic target gene even in the absence of IPTG, which is an expression inducer. The RIP protein family has been reported to possess antibacterial activity due to its ability to depurinate prokaryotic ribosomes. For instance, dianthin 30 and phytolacca antiviral protein are type I RIPs which can cleave the ribose from A-2660 of 23s rRNA of E. coliti${ }^{44}$. It has been reported that type I RIPs from Mirabilis expansa, expressed in E. coli, inhibit bacterial growth ${ }^{43}$, 45-47. Thus, we modified the specific primer $(\mathrm{F} 4 *)$ by adding nucleotides to avoid protein expression in the cloning vector. The plasmids of 16 clones (10 clones from gDNA and 6 clones from cDNA) were subjected to DNA sequencing.

\subsection{Sequence analysis}

The full-length candidate MAP30 from direct sequencing of PCR products using gDNA of $M$. charantia as a template, namely McRIP001, contains a single putative open reading frame of $861 \mathrm{bp}$ and does
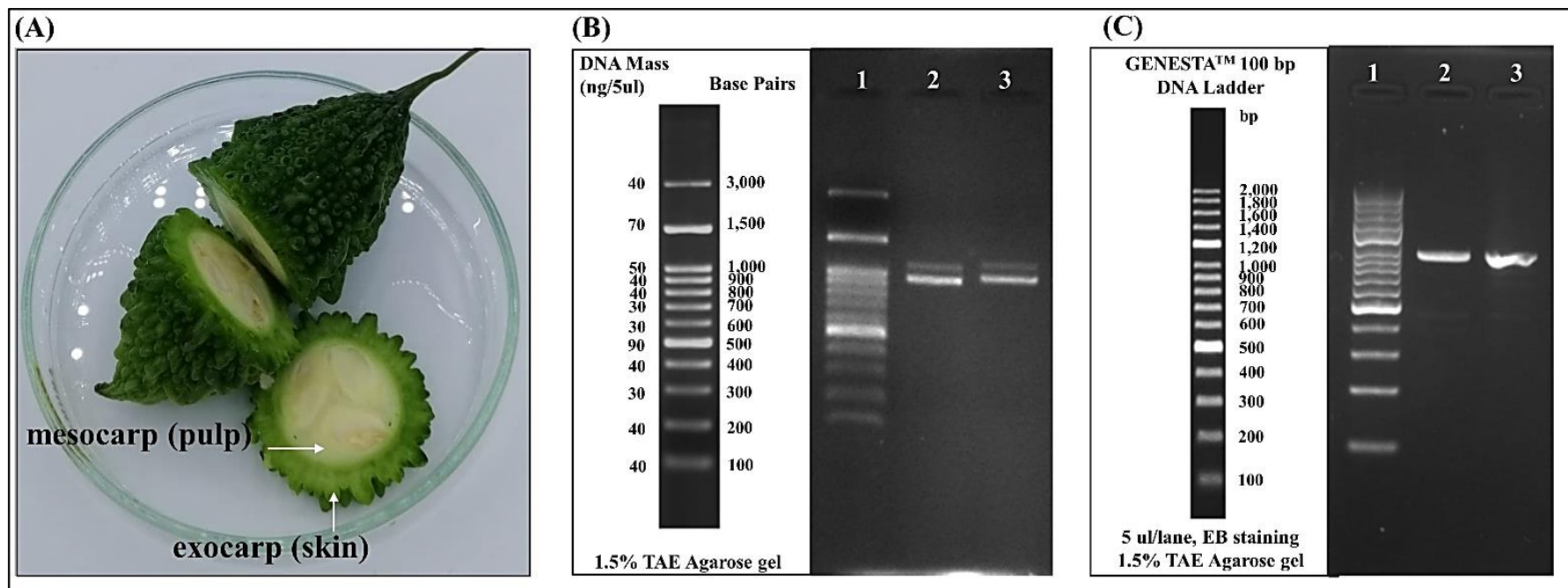

Figure 1. PCR products from DNA of Thai bitter melon. (A) Thai bitter melon fruit; (B) gel electrophoresis of PCR products from gDNA with F1-R1 pairs. Lane 1: 100 bp ladder (GeneDireX, Taiwan). Lanes 2 and 3: PCR products; (C) gel electrophoresis of PCR products from cDNA with F4-R1 pairs. Lane 1: 100 bp ladder $\left(\mathrm{GENESTA}^{\mathrm{TM}}\right)$. Lane 2: cDNA from exocarp. Lane 3: cDNA from mesocarp. 


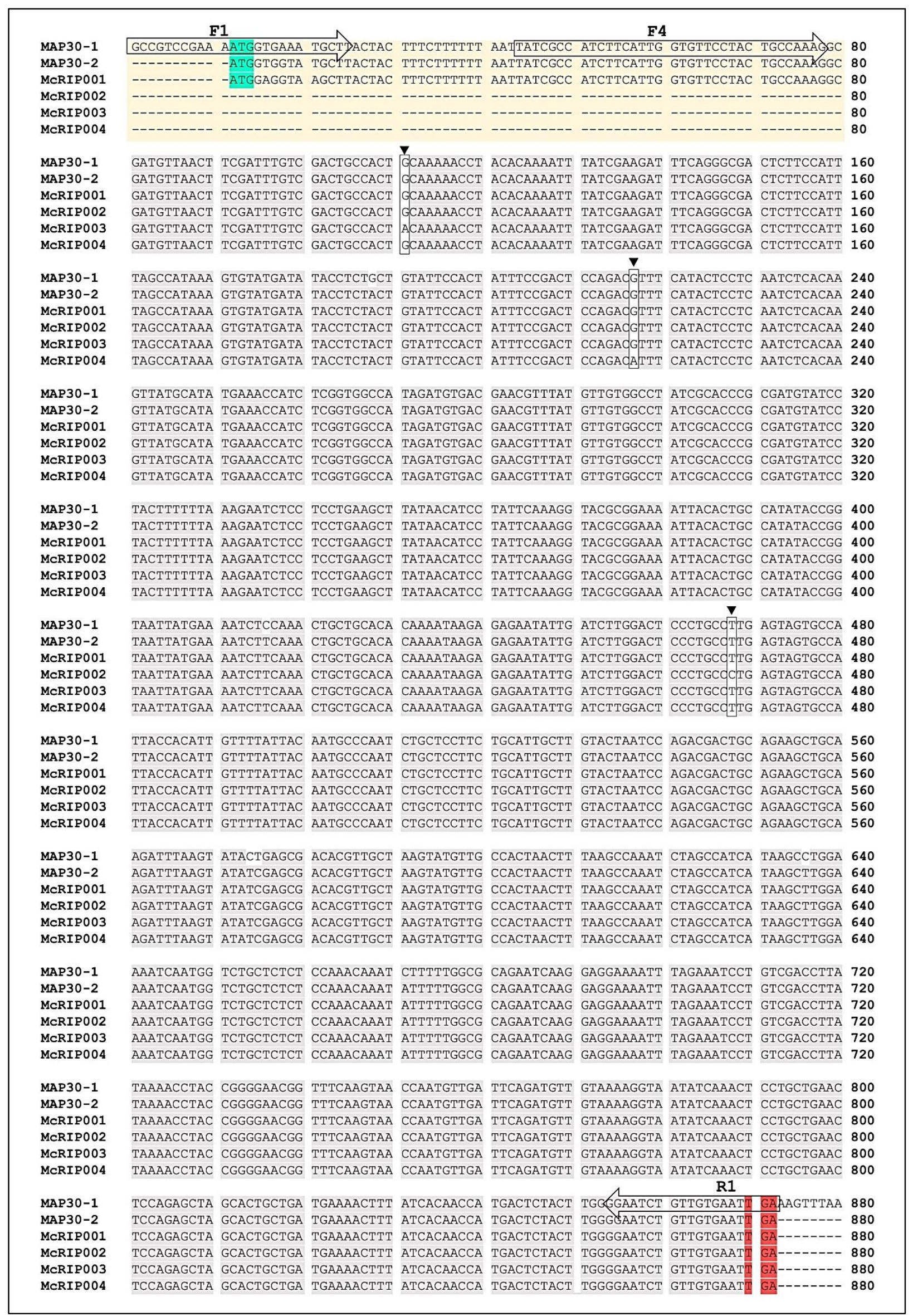

Figure 2. Multiple alignment analysis of MAP30-1, MAP30-2, McRIP001 (Genbank no. MZ399721), McRIP002 (Genbank no. MZ399722), McRIP03 (Genbank no. MZ399723), and McRIP004 (Genbank no. MZ399724). The yellow box shows a leading sequence. The arrow shows the primer region, and the black triangle shows a mutation point. Green and red colouring represent the start and stop codons, respectively. 


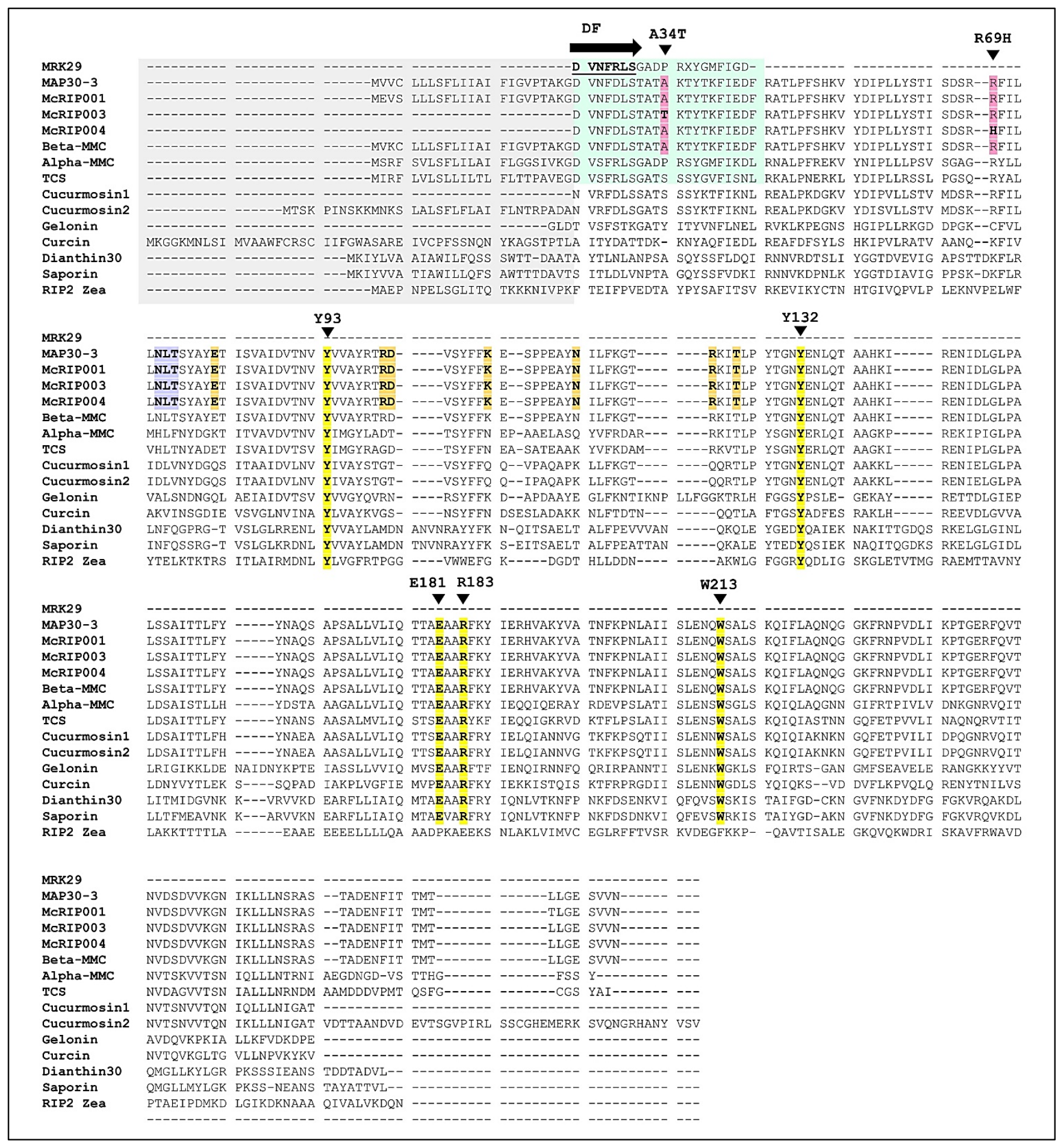

Figure 3. Multiple alignment analysis of amino acid sequences between MRK29, MAP30-3, McRIP001, McRIP003, McRIP004, $\beta$-MMC, $\alpha$ MMC, TCS, cucurmosin1, cucurmosin2, gelonin, curcin, dianthin30, saporin, and RIP2 Maize. All accession numbers of amino acid sequences are shown in the Figure 4 legend. The grey and green boxes represent a leading sequence and conserved RIP I, respectively. The pink colouring indicates the mutation point, yellow colouring indicates the active site for RNA $N$-glycosidase, purple colouring shows $N$-linked glycosylation of MAP30, and orange colouring shows LRP1 binding receptor site of MAP30.

not contain any introns. This result is consistent with previously published data for MAP $30^{48}$. MCRIP001 has double substitutions compared with MAP30-2; both are T/A (transversion) at a different site in the leading sequence (Figure 2).

Sequence analysis of 11 clones from the gDNA PCR products showed that eight clones exhibited an identity of 100\% with MAP30-2. Two clones (hereafter referred to as McRIP002) had a single substitution (T/C; transition) at the same base position, and one clone, McRIP003, had a single substitution (G/A; transition) in the mature sequence. In addition, one (McRIP004) of six clones from the cDNA PCR products exhibited a single substitution (G/A; transition) in the mature sequence. As a result, 13 of the 17 obtained nucleotide sequences were identical to MAP30, whereas others had substitutions in 
different regions and different bases in the mature sequence.

McRIP001 encodes 263 deduced amino acid sequences and is highly homologous to MAP30-3 and $\beta$ MMC (XM_022302016.1) from bitter melon, with sequence identities of $97 \%$ and 97\%, respectively. McRIP001 consists of the leading and mature sequences of 23 and 240 amino acids, respectively. The substitutions in the McRIP001 leader sequence resulted in an amino acid change from valine (V) to glutamic acid (E) and cysteine (C) to serine (S) at amino acid positions 2 (V2E) and 4 (C4S), respectively. These mutations may not alter the activity because they are not located in the mature sequence as an active form of MAP30.

Interestingly, McRIP003 and McRIP004 have amino acid variants in their mature sequences. McRIP003 has a mutated residue (A34T) in the conserved region which changes alanine (A) to threonine (T), whereas other plant type-I RIPs have proline (P), alanine, or serine at this position (Figure 3). Proline and alanine are non-polar or hydrophobic amino acids, whereas serine and threonine are polar and uncharged amino acids, respectively. Moreover, McRIP004 has a mutated residue (R69H) that changes from arginine (R) to histidine $(\mathrm{H})$. Likewise, other RIPs have a variant in this amino residue, including trichosanthin (TCS $)^{49}, \alpha$-MMC, dianthin $30^{50}$, and saporin ${ }^{51}$ (Figure 3). These sequence variations were positively charged side chain groups. In addition, McRIP002 has silent mutations that do not change amino acid residues. Sequence alignment of plant type I RIPs revealed the active sites of RNA $\mathrm{N}$ glycosidase activity, which are highly conserved among RIPs (Figure 3), including Y93, Y132, E191, R194, and W213 (MAP30-3 numbering) compared to type III RIP from Zea mays (accession no. NP001306663.1) ${ }^{19,52}$.

Amino acid alignments of MRK29 with McRIP003, McRIP004, MAP30-3, $\alpha$-MMC, and $\beta$-MMC revealed conserved regions among RIPs (Figure 3). Interestingly, MRK29 showed higher similarity to $\alpha$-MMC with an identity of $85 \%$, meanwhile lower similarity to other RIPs with an identity of 50\%-67\%. Moreover, MRK29 and $\alpha$-MMC have similar bioactivities, such as antiviral activity (HIV1) ${ }^{24,53}$. Thus, it could be hypothesised that MRK29 is a variant of $\alpha$-MMC but not MAP30. It has also been suggested that $\beta$-MMC is a MAP30 variant owing to its $99 \%$ amino acid identity ${ }^{3,54}$.

\subsection{Phylogenetic tree}

A phylogenetic tree of deduced amino acid sequences was constructed using the neighbour-joining method for plant RIPs ${ }^{8}$, including McRIP003, McRIP004, $\alpha$-MMC, $\beta$-MMC, MAP30-3, cucurmosin1, cucurmosin2, TCS, dianthin30, gelonin, and curcin, as shown in Figure 4. Type III RIP from Zea mays was used as the out-group ${ }^{52}$. As expected, McRIP003, McRIP004, $\beta$ -
MMC, and MAP30-3 were grouped in the same branch, where MAP30 and $\beta$-MMC were closely related (Figure 4). Moreover, other proteins from the same Cucurbitaceae family, including $\alpha$-MMC, TCS, cucurmosin 1 , and cucurmosin2, were grouped in the same clade. This result revealed close similarity between plant RIPs.

\subsection{Homology modelling}

The 3D structures of McRIP003 and McRIP004 were predicted by SWISS-MODEL using MAP30-3, with $99.62 \%$ amino acid identity as a template. Overall, the predicted protein structures of McRIP003 and McRIP004 were similar to those of the template. The structures consist of $\alpha$-helices, $\beta$-sheets, anti-parallel components, and loop components, as demonstrated in a previous study ${ }^{19}$ (Figure 5). Conserved amino acid residues responsible for RNA- $\mathrm{N}$-glycosidase and antiviral integrase activities, including Y93, Y123, E191, R194, and W213, were located in the cleft between the $\mathrm{N}$-terminal and C-terminal domains (Figure 5). In addition, essential conserved regions for MAP30 activity, including the $N$-linked glycosylation site (NLT) and low-density lipoprotein receptor-related protein 1 (LRP1), were superimposed well on the MAP30-3 crystal structure $^{19,55}$ (Figure 5). However, the mutated residues of candidates (A34T and $\mathrm{R} 69 \mathrm{H}$ ) were not located in these regions; thus, they might not interrupt MAP30 activity.

\section{CONCLUSIONS}

This study obtained full-length and partial sequences of putative MAP30 from Thai bitter melon. Nucleotide sequence analysis showed that most obtained sequences yielded a 100\% identity with MAP30, and three variants were found. One variant had a silent mutation. Homology modelling revealed that the mutation points do not involve RNA $N$-glycosidase active sites and may not interrupt MAP30 activity. The MAP30 sequence variants specific to Thai bitter melon can be used to design a specific primer to distinguish between Thai and Chinese bitter melon from the herbal products in the market. Moreover, MRK29 might be an $\alpha$-MMC variant because it has a similar sequence, molecular weight, and bioactivity. To confirm this hypothesis, further studies including molecular cloning and expression system are required to determine the full-length sequence and bioactivity of MRK29. Thus, the present study provides insight into the genetic information of MAP30 in Thai bitter melon and supports research and development using this plant in the future.

\section{ACKNOWLEDGEMENT}

We thank Kazuki Saito, Mami Yamazaki, 


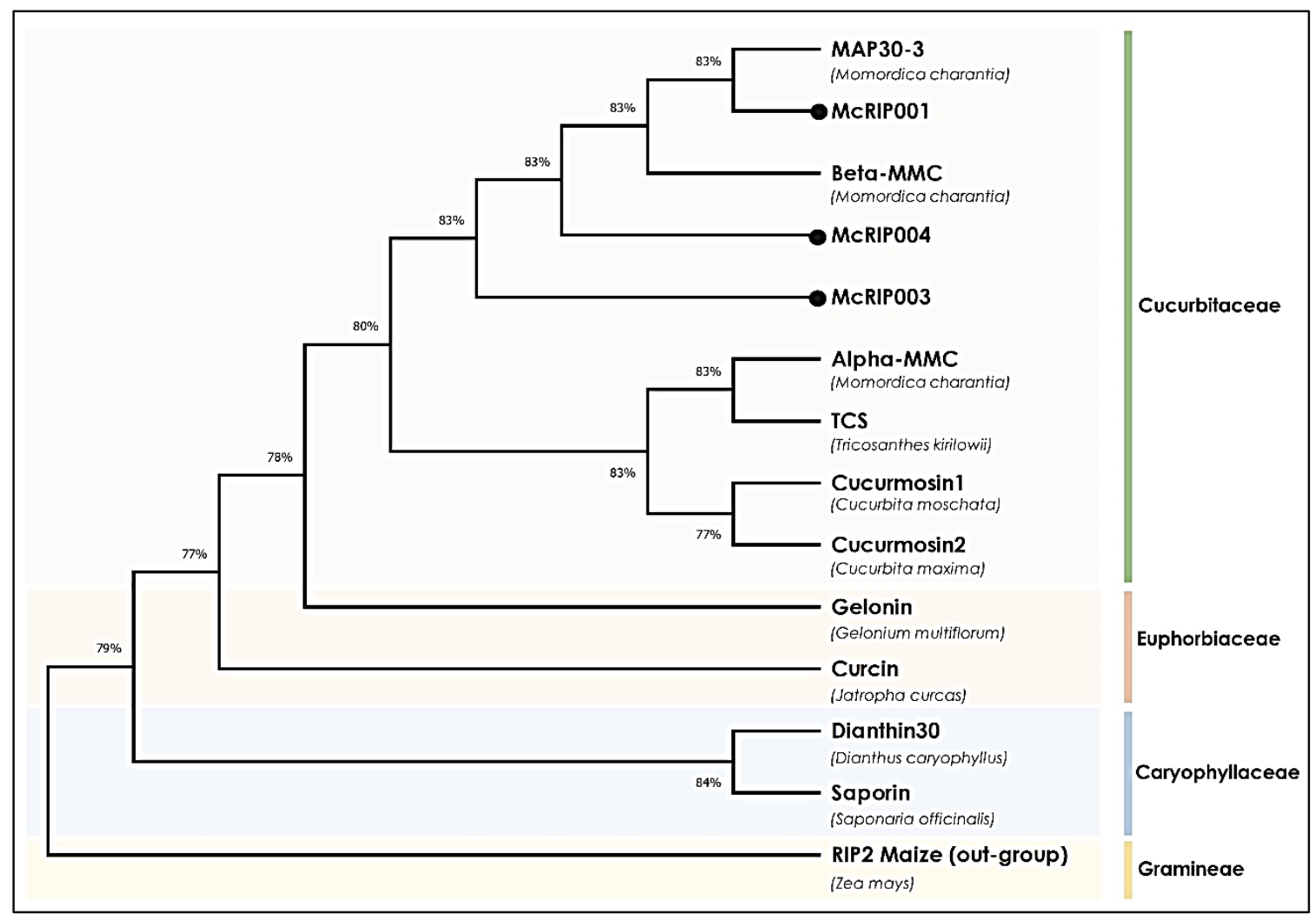

Figure 4. Phylogenetic tree using the neighbour-joining method (1000 bootstrap) analysis of sample McRIP001, McRIP003, and McRIP004 with type I RIPs, including MAP30-3, $\alpha$-MMC, $\beta$-MMC, TCS (Genbank no. AAB31048.1), cucurmosin1 (accession no. XP023005049.1), cucurmosin2 (accession no. XP023005049.1), gelonin (Genbank no. AAB47013.1), curcin (Genbank no. ACO53803.1), dianthin30 (Genbank no. CAA41953.1), and saporin (Genbank no. CAA41948.1). RIP2 Maize (accession no. NP001306663.1) was used as an out-group.

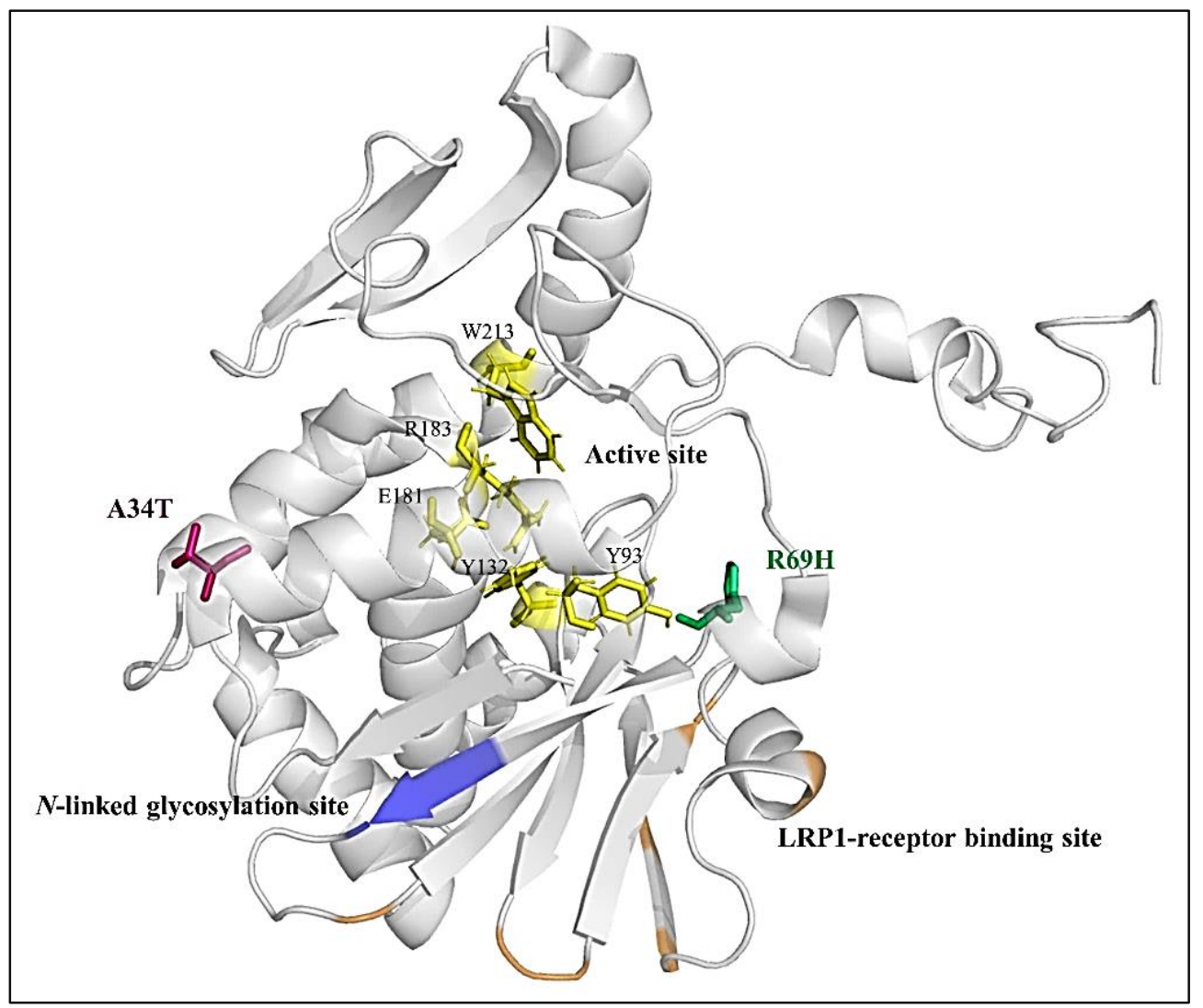

Figure 5. Schematic overlay diagram of the tertiary structure of MAP30-3 (PDB: 1d8V.1.A), McRIP003, and McRIP004. The overlay structure showed the active site of RNA $N$-glycosidase (yellow), $N$-linked glycosylation site (purple), LRP1-receptor binding site (orange), and mutated residues. 
and Yohei Shimizu, Graduate School of Pharmaceutical Sciences, Chiba University, Japan, for supporting us throughout the project.

\section{Conflict of interest}

The authors have no conflicts of interest to declare relevant to the contents of this article.

\section{Funding}

This work was financially supported by the Thailand Research Fund, the Office of the Higher Education Commission (Thailand), through a Research Grant for New Scholar (grant number MRG6180131).

\section{Ethics approval}

None to declare.

\section{Article info:}

Received June 26, 2021

Received in revised form August 7, 2021

Accepted August 12, 2021

\section{REFERENCES}

1. Raina K, Kumar D, Agarwal R. Promise of bitter melon (Momordica charantia) bioactives in cancer prevention and therapy. Semin Cancer Biol. 2016;40-41:116-29.

2. Joseph B, Jini D. Antidiabetic effects of Momordica charantia (bitter melon) and its medicinal potency. Asian Pac J Trop Dis. 2013;3(2):93-102.

3. Lee-Huang S, Huang PL, Chen H-C, Huang PL, Bourinbaiar A, Huang HI, et al. Anti-HIV and antitumor activities of recombinant MAP30 from bitter melon. Gene. 1995;161(2):151-6.

4. Stirpe F. Ribosome-inactivating proteins. Toxicon. 2004;44(4): 371-83.

5. Parkash A, Ng TB, Tso WW. Purification and characterization of charantin, a napin-like ribosome-inactivating peptide from bitter gourd (Momordica charantia) seeds. J Pept Res. 2002;59 (5):197-202.

6. Jia S, Shen M, Zhang F, Xie J. Recent Advances in Momordica charantia: Functional Components and Biological Activities. Int J Mol Sci. 2017;18(12):2555.

7. Patel S, Patel T, Parmar K, Bhatt Y, Patel Y, Patel NM. Isolation, characterization and antimicrobial activity of charantin from Momordica Charantia Linn. fruit. IJDDR. 2010;2:629-34.

8. Wang S, LiZ, Li S, Di R, Ho C, Yang G. Ribosome-inactivating proteins (RIPs) and their important health-promoting property. RSC Adv. 2016;6(52):46794-805.

9. Stirpe F, Gilabert O. Ribosome-inactivating proteins: an overview. Toxins. 2015. p. 1-29.

10. Wang S, Zheng Y, Yan J, Zhu Z, Wu Z, Ding Y. Alphamomorcharin: a ribosome-inactivating protein from Momordica charantia, possessing DNA cleavage properties. Protein Pept Lett. 2013;20(11):1257-63.

11. Yadav S, Batra J. Mechanism of anti-HIV activity of ribosomeinactivating protein, saporin. Protein Pept Lett. 2015;22(6): 497-503.

12. Puri M, Kaur I, Kanwar R, Gupta RC, Chauhan A, Kanwar J. Ribosome inactivating proteins (RIPs) from Momordica charantia for antiviral therapy. Curr Mol Med. 2009;9:1080-94.

13. Fabbrini MS, Katayama M, Nakase I, Vago R. Plant ribosomeinactivating proteins: progesses, challenges and biotechnological applications (and a few digressions). Toxins. 2017;9(10): 314.
14. Ling J, Liu W, Wang TP. Cleavage of supercoiled doublestranded DNA by several ribosome-inactivating proteins in vitro. FEBS Lett. 1994;345(2):143-6.

15. Roncuzzi L, Gasperi Campani A. DNA-nuclease activity of the single-chain ribosome-inactivating proteins dianthin30, saporin6 and gelonin. FEBS Lett. 1996;392(1):16-20.

16. Barbieri L, Ciani M, Girbés T, Liu W, Van Damme EJM, Peumans WJ, et al. Enzymatic activity of toxic and non-toxic type 2 ribosome-inactivating proteins. FEBS Lett. 2004;563(1):219-22.

17. Schrot J, Weng A, Melzig MF. Ribosome-inactivating and related proteins. Toxins. 2015;7(5):1556-615.

18. Wang YX, Jacob J, Wingfield PT, Palmer I, Stahl SJ, Kaufman $\mathrm{JD}$, et al. Anti-HIV and antitumor protein MAP30, a $30 \mathrm{kDa}$ single-strand type-I RIP, shares similar secondary structure and beta-sheet topology with the A chain of ricin, a type-II RIP. Protein Sci. 2000;9(1):138-44.

19. Wang YX, Neamati N, Jacob J, Palmer I, Stahl SJ, Kaufman JD. Solution Structure of anti-HIV1 and antitumor protein MAP30: structural insights into its multiple functions. Cell. 1999;99(4): 433-42.

20. Gu H, Lin R, Wang H, Zhu X, Hu Y, Zheng F. Effect of Momordica charantia protein on proliferation, apoptosis and the AKT signal transduction pathway in the human endometrial carcinoma Ishikawa H cell line in vitro. Oncol Lett. 2017; 13(5):3032-8.

21. Fang EF, Zhang CZY, Wong JH, Shen JY, Li CH, Ng TB. The MAP30 protein from bitter gourd (Momordica charantia) seeds promotes apoptosis in liver cancer cells in vitro and in vivo. Cancer Lett. 2012;324(1):66-74.

22. Puri M, Kaur I, Perugini MA, Gupta RC. Ribosome-inactivating proteins: current status and biomedical applications. Drug Discov Today. 2012;17(13):774-83.

23. Zeng M, Zheng M, Lu D, Wang J, Jiang W, Sha O. Anti-tumor activities and apoptotic mechanism of ribosome-inactivating proteins. Chin J Cancer. 2015;34(8):325-34.

24. Jiratchariyakul W, Wiwat C, Vongsakul M, Somanabandhu A, Leelamanit W, Fujii I, et al. HIV inhibitor from Thai bitter gourd. Planta Med. 2001;67(4):350-3.

25. Lee Huang S, Huang PL, Huang PL, Bourinbaiar AS, Chen HC, Kung HF. Inhibition of the integrase of human immunodeficiency virus (HIV) type 1 by anti-HIV plant proteins MAP30 and GAP31. Proc Natl Acad Sci USA. 1995;92(19):8818-22.

26. Zhu F, Zhu P-X, Xu F, Che Y-P, Ma Y-M, Ji Z-L. Alphamomorcharin enhances Nicotiana benthamiana resistance to tobacco mosaic virus infection through modulation of reactive oxygen species. Mol Plant Pathol. 2020;21(9):1212-26.

27. Yang T, Meng Y, Chen L-J, Lin H-H, Xi D-H. The Roles of Alpha-Momorcharin and Jasmonic Acid in Modulating the Response of Momordica charantia to Cucumber Mosaic Virus. Front Microbiol. 2016;7:1796.

28. Meng Y, Lin S, Liu S, Fan X, Li G, Meng Y. A novel method for simultaneous production of two ribosome-inactivating proteins, $\alpha$-MMC and MAP30, from Momordica charantia L. PLoS One. 2014;9(7):e101998.

29. Deng N, Sun Y, Liu M, He Q, Wang L, Zhang Y, et al. Alphamomorcharin regulates cytokine expression and induces apoptosis in monocytes. Immunopharmacol Immunotoxicol. 2019; 41(2):258-66.

30. Chen YJ, Zhu JQ, Fu XQ, Su T, Li T, Guo H, et al. Ribosomeinactivating protein $\alpha$-momorcharin derived from edible plant Momordica charantia induces inflammatory responses by activating the NF-kappa B and JNK pathways. Toxins. 2019; 11(12):694.

31. Pornsuriya P, Numuen C. Phenotypic diversity and classification of Thai bitter melon (Momordica charantia L.) landraces from three provinces in central region of Thailand. IJAT. 2011;7:849-56.

32. Poolperm S, Jiraungkoorskul W. An Update Review on the 
Anthelmintic Activity of Bitter Gourd, Momordica charantia. Pharmacogn Rev. 2017;11(21):31-4.

33. Patel R, Mahobia N, Upwar N, Waseem N, Talaviya H, Patel Z. Analgesic and antipyretic activities of Momordica charantia Linn. fruits. J Adv Pharm Technol Res. 2010;1(4):415-8.

34. Leung L, Birtwhistle R, Kotecha J, Hannah S, Cuthbertson S. Anti-diabetic and hypoglycaemic effects of Momordica charantia (bitter melon): a mini review. Br J Nutr. 2009;102(12):1703-8.

35. Ahmad N, Hasan N, Ahmad Z, Zishan M, Zohrameena S. Momordica charantia: For traditional uses and pharmacological actions. J Drug Deliv Ther. 2016;6(2)40-4.

36. Kaur I, Gupta RC, Puri M. Ribosome inactivating proteins from plants inhibiting viruses. Virol Sin. 2011;26(6):357-65.

37. Kushwaha GS, Pandey N, Sinha M, Singh SB, Kaur P, Sharma $\mathrm{S}$, et al. Crystal structures of a type-1 ribosome inactivating protein from Momordica balsamina in the bound and unbound states. Biochim Biophys Acta. 2012;1824(4):679-91.

38. Urasaki N, Takagi H, Natsume S, Uemura A, Taniai N, Miyagi $\mathrm{N}$, et al. Draft genome sequence of bitter melon (Momordica charantia), a vegetable and medicinal plant in tropical and subtropical regions. DNA Res. 2017;24(1):51-8.

39. TA H. BioEdit: a user-friendly biological sequence alignment editor and analysis program for Windows 95/98/NT. Nucleic Acids Symp Ser. 1999;41:95-8.

40. Kumar S, Stecher G, Li M, Knyaz C, Tamura K. MEGA X: Molecular Evolutionary Genetics Analysis across Computing Platforms. Mol Biol Evol. 2018;35(6):1547-9.

41. Arnold K, Bordoli L, Kopp J, Schwede T. The SWISS-MODEL workspace: a web-based environment for protein structure homology modelling. Bioinformatics. 2006;22(2):195-201.

42. Lee Huang S, Huang PL, Nara PL, Chen HC, Kung HF, Huang $\mathrm{P}$, et al. MAP 30: a new inhibitor of HIV-1 infection and replication. FEBS Lett. 1990;272(1-2):12-8.

43. Vepachedu R, Park SW, Sharma N, Vivanco JM. Bacterial expression and enzymatic activity analysis of ME1, a ribosomeinactivating protein from Mirabilis expansa. Protein Expr Purif. 2005;40(1):142-51.

44. Hartley MR, Legname G, Osborn R, Chen Z, Lord JM. Singlechain ribosome inactivating proteins from plants depurinate Escherichia coli 23 S ribosomal RNA. FEBS Lett. 1991;290(1-2): 65-8.

45. Kataoka J, Habuka N, Furuno M, Miyano M, Takanami Y,
Koiwai A. DNA sequence of mirabilis antiviral protein (MAP), a ribosome-inactivating protein with an antiviral property, from mirabilis jalapa L. and its expression in Escherichia coli. J Biol Chem. 1991;266(13):8426-30.

46. Habuka N, Akiyama K, Tsuge H, Miyano M, Matsumoto T, Noma M. Expression and secretion of mirabilis antiviral protein in Escherichia coli and its inhibition of in vitro eukaryotic and prokaryotic protein synthesis. J Biol Chem. 1990;265(19): 10988-92.

47. Girbés T, Barbieri L, Ferreras M, Arias FJ, Rojo MA, Iglesias R. Effects of ribosome-inactivating proteins on Escherichia coli and Agrobacterium tumefaciens translation systems. J Bacteriol. 1993;175(20):6721-4.

48. Wang F, Chi CY, Wang LY, Qiao Y, Jin XX, Ding G-H. Gene cloning and expression of MAP30 in Pichia pastoris. Biotechnol Biotechnol Equip. 2014;28(1):136-9.

49. Zheng H, Wang B, Shaw P, Yeung H. Cloning and DNA sequencing of the gene encoding trichosanthin. Acta Genetica Sinica. 1994;21(1):42-51

50. Legname G, Bellosta P, Gromo G, Modena D, Keen JN, Roberts LM, et al. Nucleotide sequence of cDNA coding for dianthin30, a ribosome inactivating protein from Dianthus caryophyllus. BBA. 1991;1090(1):119-22.

51. Fordham-Skelton AP, Taylor PN, Hartley MR, Croy RR. Characterization of saporin genes: in vitro expression and ribosome inactivation. MGG. 1991;229(3):460-6

52. Yang Y, Mak ANS, Shaw PC, Sze KH. Solution structure of an active mutant of Maize ribosome-inactivating protein (MOD) and its interaction with the ribosomal stalk protein P2. J Mol Biol. 2010;395(5):897-907.

53. Zheng YT, Ben KL, Jin SW. Alpha-momorcharin inhibits HIV-1 replication in acutely but not chronically infected T-lymphocytes. Acta Pharmacol Sin. 1999;20(3):239-43.

54. Xiong SD, Yu K, Liu XH, Yin LH, Kirschenbaum A, Yao S, et al. Ribosome-inactivating proteins isolated from dietary bitter melon induce apoptosis and inhibit histone deacetylase- 1 selectively in premalignant and malignant prostate cancer cells. Int J Cancer. 2009;125(4):774-82.

55. Liu B, Zhang Z, Lu S, He Q, Deng N, Meng H, et al. In-silico analysis of ligand-receptor binding patterns of $\alpha$-MMC, TCS and MAP30 protein to LRP1 receptor. J Mol Graph Model. 2020;98:107619. 